\title{
Refletindo sobre o ensino de línguas estrangeiras na educação de jovens e adultos: experiências no Cap/ufrgs
}

$N$ atalia Labella-Sánchez ${ }^{*}$ Letícia Pires D 'A ndrea**

R esumo: Este trabalho objetiva compartilhar as experiências iniciais do ensino de línguas estrangeiras (espanhol e inglês) no primeiro semestre de trabalhos com a educação de jovens e adultos no CA p/U FR GS. Para isso, consideramos o contexto no qual se insere esse ensino fazendo uma breve retomada do ensino de línguas no Brasil, no ensino de jovens e adultos até chegar à Proposta de Implementação feita pelo Colégio. Em nossas discussões, procuramos refletir sobre o papel e o espaço da língua estrangeira em um contexto de ensino que se propõe a ser flexível, aberto à interdisciplinaridade e à constante troca de experiência entre os professores, bem como pensar no ensino simultâneo dessas duas línguas nesse espaço.

Palavras-chave: Ensino de jovens e adultos, Ensino de línguas estrangeiras, Especificidades das línguas estrangeiras.

Professora substituta de Língua Espanhola no CAp/U FRGS em 2008. Especialista em Ensino de Língua Estrangeira e M estre em Estudos da Linguagem pela U niversidade Estadual de Londrina. E-mail: natalia.labella@yahoo.com.br

** Professora substituta de Língua Inglesa no CAp/U FRGS em 2008. M estre em Ensino de Língua Inglesa e Estudos de L ingüística A plicada pela L ondon M etropolitan U niversity, Inglaterra. E-mail: leticiapd@gmail.com 


\begin{abstract}
A bstract: This article aims at sharing the first experiences of teaching foreign languages (Spanish and English) in the first semester of work with theyouth and adult schooling at CAp/U FR GS. For that, we have briefly analyzed the teaching of foreign languages in Brazil and in the youth and adults schooling context. We have also explained the school's I mplementation Project. I n our discussion, we reflect about the role and space of foreign languages in a schooling context which is flexible, open to interdisciplinarity and to the constant experience sharing among teachers, in addition, we reflect about the simultaneous teaching of both languages in this environment.
\end{abstract}

Keywords: Youth and adult schooling, Foreign language teaching, Specificities of foreign languages.

\title{
Introdução
}

Com a recente iniciativa de oferecimento da Educação de JovenseAdultos (EJA) no Colégio deA plicação daU FR GS (CAp/ UFR GS) e inspiradas na forma de trabalho proposta pelo Colégio, percebemos a importância de refletirmos sobre como as línguas estrangeiras são vistas dentro da Proposta de I mplementação do Colégio. Além disso, este texto permite-nos refletir sobre a nossa prática dentro do projeto, sempre considerando que ela ocorre dentro de um universo maior, composto por diferentes componentes curriculares e por um grupo grande de colegas.

Para a compreensão do papel e do lugar das línguas estrangeiras (LE) dentro desse universo, entendemos que é necessária uma contextualização prévia, de modo que, para entender os fatos presentes, precisamos entender parte da história que a compõe.

Assim, iniciaremos fazendo um breve histórico da EJA na história da educação brasileira. D epois, discorreremos um pouco sobre a história do ensino das línguas estrangeiras no Brasil, já 
que compreender a trajetória da LE em nossa educação fornecenos alguns subsídios para refletir sobre o espaço e a importância que ensino de LE pode ter na EJA.

$\mathrm{N}$ a seqüência, apresentaremos a Proposta de I mplementação da M odalidade de E ducação para Jovens e A dultos no C olégio de A plicação da UFR GS - EJA/CA p/U FR GS (doravante Proposta de I mplementação da EJA-CAp/U FR GS), além da descrição de outros aspectos que entendemos relevantes como organização dos componentes curriculares, planejamento e organização dos trabaIhos semanais, formas de acesso aos cursos, entre outros.

Em seguida, detalharemos a forma como estão inseridas as línguas estrangeiras no projeto e abordaremos algumas especificidades relativas aos idiomas ofertados, no caso, espanhol e inglês. Por fim, realizaremos algumas reflexões acerca do trabalho realizado até 0 momento.

\section{Breve Histórico da Educação de Jovens e Adultos no Brasil}

No segundo semestre de 2008, o CAp/U FR GS iniciou o seu projeto próprio de Educação de Jovens e Adultos. D o início de 2007 até o primeiro semestre de 2008, o Colégio de A plicação trabalhava com essa modalidade em parceria com a Escola Técnica da UFRGS, atendendo alunos tanto da EJA quanto do Programa de Educação Profissional Técnica (PR OEJA). Ao assumir esse projeto, o CA p/U FR GS entende que "Esta disposição vem ao encontro das necessidades da sociedade e do mercado de trabalho, que está gradualmente exigindo dos trabalhadores melhor formação pessoal etécnica" (COLÉGIO DE APLICAÇÃO, 2008, p. 4).

Se atualmente a EJA é amplamente apoiada e incentivada na esfera pública, o Parecer CN E/CEB № 11/2000, referente às D iretrizes Curriculares $\mathrm{N}$ acionais para a Educação de J ovens e Adultos mostra que nem sempre foi assim. 
A primeira proposta de EJA no Brasil foi feita em 1879, embora de modo precário e desarticulado. V árias tentativas de consolidação dessa modalidade de ensino foram realizadas ao longo de mais de nove décadas, travada - em muitos momentos - por decisões e interesses políticos. ${ }^{1}$ Somente em 1971, com a aprovação da Lei 5.692/71, a educação para jovens e adultos ganha bases legais próprias, com interesses voltados à qualificação de mão de obra e sob o jugo das reformas autoritárias impostas pelo regime militar. Com a R eforma Constitucional de 1988, no Art. 214, o governo comprometeu-se a estabelecer um plano de educação objetivando a erradicação do analfabetismo e a universalização do atendimento escolar. Com a L ei de Diretrizes e Bases (LDB) de 1996, o governo evidencia uma necessidade de "política educacional integrada da EJA de modo a superar o isolamento a que ela foi confinada em vários momentos históricos da escolarização brasileira" (PARECER CNE/CEB 11/2000, p. 2324).

Com a LDB de 1996, vários documentos relativos ao ensino - incluindo o ensino de línguas estrangeiras - foram produzidos e publicados. Como exemplo, temos a publicação dos Parâmetros Curriculares para Ensino Fundamental (1998) e, no ano seguinte, os Parâmetros Curriculares para Ensino M édio (PCN e PCN EM , respectivamente). E $m$ 2006, publicaram-se as O rientações Curriculares para o Ensino M édio (OCEM), com um capítulo específico para o ensino de línguas estrangeiras - assim como há também nos documentos anteriores - e um outro específico para o ensino da língua espanhola. As propostas e orientações desses documentos também se estendem à educação de jovens e adultos, já que a EJA, de acordo com a L ei 9.131/96, passa a ser uma modalidade da educação básica nas etapas do ensino fundamental e médio.

Contudo, considerando as especificidades próprias do ensino na EJA, percebeu-se a necessidade de se criarem diretrizes

Para um panorama mais completo sobre a EJA durante essas nove décadas ( de 1879 a 1970), cf. http://portal.mec.gov.br/secad/arquivos/pdf/eja/legislacao/parecer_11_ 2000.pdf (p. 13-20). A cesso em: 06 set. 2008. 
específicas para esse contexto. R esultado dessas diretrizes foi a publicação de propostas curriculares específicas para o ensino fundamental na EJA. Em 2002, publicaram-se a Proposta Curricular para a Educação de J ovens e Adultos para o primeiro segmento ( 1 a à 4 a série) ${ }^{2}$ e para 0 segundo segmento ( 5 a a $8^{\underline{a}}$ série)..$^{3} \mathrm{O}$ segundo segmento é composto por 3 volumes. A língua estrangeira é contemplada em um capítulo específico do 2 ำ volume. ${ }^{4}$

\section{0 ensino de línguas estrangeiras e a Educação de Jovens e Adultos}

Para falar do ensino de LE na EJA, não podemos deixar de contextualizar brevemente a atribulada trajetória das LE no contexto de ensino brasileiro. 0 espaço aparentemente definitivo conquistado pelas LE é algo muito recente na educação brasileira. Inseridas nos currículos escolares pelo governo de D. João VI (1809), as línguas estrangeiras foram consideradas de diversas maneiras pelos diferentes governos e reformas educacionais.

Segundo Chagas (1979), é com a R eforma de Francisco de Campos, em 1931, que as línguas estrangeiras modernas ocupam uma posição análoga à das línguas clássicas. 0 estudo de francês, inglês e alemão torna-se obrigatório, junto ao latim e ao grego. A lém disso, Celani (1994) aponta que foi com essa reforma que o ensino de línguas melhorou e se atualizou didática e metodologicamente. Com a R eforma C apanema, em 1942, pela primeira vez a língua espanhola é ofertada no currículo, tornando-se obrigatória junto ao ensino de francês, inglês e latim.

0 ensino das línguas estrangeiras permaneceu estável até a aprovação da LDB de 1961, quando as LE deixaram de

2 Disponível em: http://portal.mec.gov.br/secad/arquivos/pdf/eja/propostacurricular/ primeirosegmento/proposta curricular.pdf. Acesso em: 08 nov. 2008.

3 D isponível em: http://portal.mec.gov.br/secad/arquivos/pdf/eja_livro_01.pdf. Acesso em: 08 nov. 2008.

4 O texto está disponível em: http://portal.mec.gov.br/secad/arquivos/pdf/eja/proposta curricular/segundo segmento/vol2_lingua estrangeira.pdf. Acesso em: 08 nov. 2008. 
pertencer ao núcleo comum das disciplinas e passaram a fazer parte do núcleo diversificado. Para Picanço (2003), desde 1961 deixou de haver uma postura clara com relação ao ensino de línguas. Além disso, a autora chama a atenção para o fato de que o texto da LD B de 1961 sugere o ensino de uma língua estrangeira desde que houvesse professores capacitados para ensiná-la, dando indicativos de que o governo preferia atribuir a ausência ou presença do ensino de línguas estrangeiras nas escolas à qualidade dos professores e, ao mesmo tempo, eximindo-se da responsabilidade de formá-los e capacitá-los.

A única língua sobrevivente à lei foi o inglês, segundo $L$ effa (1999), embora também com muitas barreiras impostas pela desvalorização que as línguas estrangeiras sofreram:

comparada à R eforma Capanema eà L D B que veio em seguida, a lei de 1961 éo começo do fim dosanos dourados das línguas estrangeiras. (...) [A] LD B do início da década de 60 reduziu o ensino de línguas a menos de $2 / 3$ do quefoi durantea R eforma Capanema (LEFFA, 1999, p. 20).

M esmo enfrentando dificuldades, o ensino hegemônico do inglês se fortaleceu e este se tornou praticamente o único idioma oferecido nas escolas.

Somente com a LBD de 1996 é que a situação do ensino de LE é revista. Ainda que a LE continue sendo mantida na parte diversificada do currículo

será incluído, obrigatoriamente, a partir da quinta série, o ensino de pelo menos uma língua estrangeira moderna, cuja escolha ficará a cargo da comunidade escolar, dentro das possibilidades da instituição (BRASIL, 1996, Art. 26, § 5o) (grifo nosso).

Para o ensino médio a proposta é parecida, com a diferença de que devido à aprovação da L ei $11.161 / 05^{5}$, a língua estrangeira moderna de oferta obrigatória, porém de escolha facultativa por parte do aluno é a língua espanhola.

Com base nesse sucinto histórico do ensino de línguas no Brasil, podemos dizer que a relação entre línguas estrangeiras

5 Disponível em: http://www.planalto.gov.br/ccivil_03/_Ato2004-2006/2005/L ei/ L 111 61.htm. Acesso em: 10 set. 2008. 
nas salas de aula da EJA é bastante influenciada pelo que aconteceu e acontece no ensino regular. Parecenos que o fato de a LE ter sido "marginalizada" durante tantas décadas, fez com que o texto da Resolução CNE/CEB no 1, de 05/07/20006, a qual estabelece as Diretrizes Curriculares $\mathrm{N}$ acionais para a E ducação de Jovens e Adultos, procura frisar o lugar das LE na EJA. Porém, desde nosso ponto de vista, o documento acaba suscitando algumas dúvidas e, de certa forma, revisitando questões históricas quanto ao tratamento dado às línguas estrangeiras.

D uas questões chamam sobremaneira a nossa atenção. A primeira é o fato de que a única disciplina citada explicitamente nessa R esolução é a língua estrangeira. Todas as demais ficaram subentendidas na parte em que o documento se refere a elas como componentes curriculares constantes no Art. 26, 27, 28 e 32 da LDB (ressaltamos, mais uma vez, que as línguas estrangeiras fa zem parte do Art. 26, mencionadas claramente no § 50 da LD B). I sso, ao nosso ver, dá-nos margem a interpretar que essa R esolução não entende as línguas estrangeiras como parte certamente integrada aos componentes curriculares, senão como algo a ser tratado à parte.

A segunda questão, ainda mais inquietante que a primeira, diz respeito ao Art. 20, § 2o da R esolução: "A Língua Estrangeira, nesta etapa do ensino, é de oferta obrigatória e de prestação facultativa por parte do aluno" (grifo nosso), associado ao Art. 21, § 2ำ que diz: "A língua estrangeira é componente obrigatório na oferta e prestação de exames supletivos" (grifo nosso). Como entender a R esolução? Se ela se baseia, em grande parte, na L DB de 1996 para estabelecer as D iretrizes Curriculares para EJA, por que - mais uma vez - as línguas estrangeiras aparecem como algo aparentemente externo ao currículo e de prestação facultativa por parte do aluno? N ão é incoerente que 0 aluno possa optar por estudá-la, mas seja obrigado a realizar provas de LE nos exames supletivos?

6 Disponível em: http://portal.mec.gov.br/cne/arquivos/pdf/CEB012000.pdf. A cesso em 06 set. 2008. 
0 mais surpreendente é que o Parecer CNE/CEB no 11 / 2000 sobre as D iretrizes Curriculares para EJ A7 menciona constantemente a importância de resgate à cidadania, a atualização de conhecimentos, a necessidade de educação permanente dirigida às necessidades das sociedades modernas, o trabalho com múltiplas linguagens visando dimensões do trabalho e cidadania, entre tantas outras.

Além disso, os PCN , os PCN EM , as OCEM e as Propostas C urriculares para a Educação de J ovens e A dultos entendem - e nós também - o ensino de línguas estrangeiras como algo integrado ao componente curricular e como uma disciplina que, embora componha a parte diversificada do currículo, é tão essencial quanto todas as demais contribuindo para a formação de um aluno consciente e cidadão, criando possibilidades de fazêlo refletir sobre a sua própria cultura a partir da compreensão da cultura de outros, viabilizando o acesso a novas informações disponibilizadas em língua estrangeira.

\section{Oportunizando a Educação de Jovens e Adultos no CAp-UFRGS}

\section{0 projeto de implementação da Educação de Jovens e Adultos no CAp}

Como visto sucintamente no início deste artigo, a fim de atender reivindicações de seus servidores e comunidade, desde 1984, a UFRGS tem apresentado iniciativas que envolvem a Educação de J ovense A dultos. $O$ documento del mplementação da EJA-CAp/U FR GS retoma esse compromisso ao assumir que essa é uma forma de suprir uma lacuna na formação e qualificação dos servidores da própria universidade e também da comunidade em geral.

7 Disponível em: http://portal.mec.gov.br/secad/arquivos/pdf/eja/legislacao/parecer _11_2000.pdf. Acesso em: 06 set. 2008. 
Essa Proposta defende a autonomia de seus professores, estagiários e pesquisadores de modo a promover o fazer pedagógico e estimular diferentes projetos em suas linhas metodológicas, possibilitando aos envolvidos pensar em "um modelo pedagógico próprio a fim de criar situações pedagógicas e satisfazer necessidades de aprendizagem de jovens e adultos" (PARECER CNE/CEB no 11/2000, p. 9, grifos do autor).

Propõe-se não apenas oportunizar escolarização para jovens e adultos de sua comunidade, mas também criar espaço para a construção de conhecimentos sobre esta prática e, assim, ampliar a oferta de tais práticas e pesquisas docentes na universidade. Tal autonomia proporciona

a proposição de atividades pedagógicas que incluam o aluno trabalhador como agente no processo de aprendizagem, um ser concreto, portador de uma bagagem de experiências, de ideias eopiniões, desejos e resistências, que assim podem encontrar espaço, oportunidades e novos veículos para sua expressão. (COLÉGIO DE APLICAÇÃO, 2008, p. 7).

A proposta pedagógica da EJA no CAp/U FR GS leva em consideração a individualidade do aluno e seu ritmo de aprendizagem e prevê programas organizados em etapas de complexidade crescente, em que o processo educativo vise privilegiar ações interdisciplinares e inserir no currículo aspectos fundamentais da cultura geral e local, e, assim, incentivar para que os saberes e experiências de vida trazidas pelos alunos e professores contribuam para a construção do processo de ensino.

A presente legislação brasileira permite autonomia a instituições federais no tocante "a organização de cursos, sua duração e estrutura, respeitadas as orientações e diretrizes nacionais, faz parte da autonomia dos entes federativos" (PARECER CNE/ CEB no 11/2000, p. 31). Portanto, o CA /U FR GS decidiu estruturar a EJA em níveis semestrais. O Ensino Fundamental é dividido em quatro níveis semestrais e o Ensino M édio se divide em três níveis. A baixo segue uma tabela explicitando a divisão indicada pela Proposta de Implementação da EJA-CAp-U FR GS: 


\begin{tabular}{|c|c|}
\hline ENSINO FUNDAMENTAL & ENSINO MÉDIO \\
\hline Níveis e anos correspondentes & Níveis e anos correspondentes \\
\hline $\begin{array}{l}\text { Nível } 1 \text { (EF1): } 1^{\circ}, 2^{\circ} \text { e } 3^{\circ} \text { anos iniciais } \\
\text { Nível } 2(\mathrm{EF} 2): 4^{\circ} \text { e } 5^{\circ} \text { anos iniciais } \\
\text { Nível } 3(\mathrm{EF} 3): 6^{\circ} \text { e } 7^{\circ} \text { anos } \\
\text { Nível } 4(\mathrm{EF} 4): 8^{\circ} \text { e } 9^{\circ} \text { anos }\end{array}$ & $\begin{array}{l}\text { Nível } 1 \text { (EM1): } 1^{\mathrm{a}} \text { série } \\
\text { Nível } 2(\mathrm{EM} 2): 2^{\mathrm{a}} \text { série } \\
\text { Nível } 3 \text { (EM3): } 3^{\mathrm{a}} \text { série }\end{array}$ \\
\hline
\end{tabular}

Q uadro 1 - D ivisão indicada pela Proposta de Implementação da EJA-CA p/ UFRGS.

No sentido de organizar as diferentes áreas de conhecimento e ao mesmo tempo integrá-las, a Proposta de I mplementação prevê os seguintes componentes curriculares para todos os níveis:

- C omunicação: Língua Portuguesa, Línguas Estrangeiras e suas respectivas Literaturas.

- Ciências Exatas e da N atureza: M atemática, Química, Física e Biologia.

- Ciências H umanas H istória, Geografia, Filosofia e Sociologia.

- Expressão e M ovimento: Artes V isuais, Teatro, Educação Musical e Educação Física.

O s níveis 1 e 2 do Ensino Fundamental trabalham junto a uma professora alfabetizadora e, a partir do N ível 3, os alunos passam a ter aula com mais professores, visto que a cada dia da semana um dos componentes curriculares é responsável pelas aulas.

Também estão previstas ofertas de oficinas, as quais têm 0 objetivo de desenvolver habilidades de pensamento e atender alunos com dificuldades cognitivas, além de proporcionarem um tempo adicional para atividades diferenciadas. A frequência a essas oficinas é de caráter facultativo e têm suas características como duração e necessidades definidas pelo grupo de professores, sem vinculação com a semestralidade. Essas oficinas são também oferecidas aos alunos do EF 1 e EF2, facilitando o contato desses alunos com os demais professores e alunos. Tal sistema propicia uma maior interação entre as turmas e oportuniza um espaço de troca de saberes e experiências de vida trazidas pelos alunos e professores. 
Com relação ao planejamento das aulas e das atividades, semanalmente a equipe de professores da EJA-CAp se reúne para discutir possíveis projetos, encaminhamentos e dividir experiências. Os professores de cada componente curricular, por sua vez, também contam com reuniões semanais para planejamento das aulas e divisão interna da carga horária.

O CAp/U FR GS disponibiliza 20 vagas para o EF1 e 30 vagas para os demais níveis semestralmente. 0 preenchimento ocorre mediante inscrição por parte dos interessados e a realização de um sorteio público.

\section{O espaço das línguas estrangeiras na Proposta de Implementação da EJA-CAp-UFRGS}

Como mencionado anteriormente, dentro da Proposta de Implementação da EJA-CAp/U FRGS, as línguas estrangeiras têm seu lugar junto ao componente curricular de Comunicação, formado por três professores: um professor de Língua Portuguesa e Literatura, uma professora de Espanhol e uma professora de Inglês.

A oferta de mais de uma LE no currículo da EJA-CAp foi determinada pela Comissão de Ensino do CAp. Considerando que no projeto anterior vinculado à Escola Técnica da U FR GS a única língua estrangeira ofertada era o Espanhol, a entrada de, pelo menos, mais uma língua estrangeira - neste caso o Inglês - revela a concepção do Colégio quanto à importância do ensino de LE para formação dos alunos. ${ }^{8}$

A carga horária total semanal é igualitariamente dividida entre os quatro componentes curriculares. D entro disso, cada componente curricular possui uma carga horária semanal de $5 \mathrm{~h}$, sendo esta dividida em 4 horas presenciais e 1 hora não-presencial. 0 ensino não-presencial ocorre de forma integrada às atividades presencias a partir do uso de ambientes virtuais ou

8 A creditamos, também, que o fato de o CAp/U FRGS apresentar uma proposta plurilíngue há anos ensinando Alemão, Francês, Espanhol e Inglês em diferentes anos e séries refletiu na decisão da Comissão de Ensino. 
materiais impressos. A divisão interna dessa carga horária é decidida pelos professores de cada componente curricular, sempre de acordo com as demandas e propostas de trabalho. I sso nos permite certa flexibilização, diferentemente da divisão tradicional em períodos, em que os professores têm que adequar seus projetos e planos de aula à carga horária determinada pelas escolas.

\section{Compartilhando reflexões a partir da experiência inicial}

É bastante desafiador compartilhar experiências vivenciadas em um período tão curto de trabalho. Por outro lado, entendemos que socializá-las por meio deste texto é uma forma de refletirmos sobre nossa própria prática. Isso nos permite ter mais consciência da relação entre as propostas teóricas e o que foi possível realizar até 0 momento.

Entre os desafios, está o fato de que, como primeira experiência, cabe a este grupo inicial de professores definir e organizar os conteúdos que serão trabalhados, sem uma base anterior para comparação, acréscimos e/ou modificações.

A lém disso, uma característica do corpo docente que atua nos componentes curriculares da EJA-CAp/U FR GS é o fato de que apenas uma minoria desses professores é efetiva. ${ }^{9} \mathrm{O}$ componente curricular $\mathrm{C}$ omunicação, por exemplo, formado pelas áreas de Língua Portuguesa, Línguas Estrangeiras (Língua Espanhola e Inglesa) e respectivas literaturas, tem apenas um professor efetivo.

Essa característica pode criar um contexto bastante instável de continuidade, já que a qualquer momento e principalmente no final de cada semestre pode haver saída e troca de professores. Essa realidade reforça ainda mais a necessidade

9 No segundo semestre de 2008, dos 16 professores atuantes na EJA-CAp/UFR GS apenas quatro eram professores efetivos. 
dessa experiência inicial. Em contextos de ensino em que as aulas se baseiam na sequência de conteúdos oferecidos por um livro didático (LD), essas dificuldades são amenizadas por um lado (já que a progressão linear é garantida), mas aumentadas por outro, pois muitas vezes o LD engessaria as propostas do grupo de trabalho. ${ }^{10}$

Como visto no item anterior sobre as características do Projeto de I mplementação da EJA-CA p/U FR GS, inserimo-nos num contexto de ensino e aprendizagem amplo, em que se valoriza "a autonomia no fazer pedagógico". D entro desse princípio, compartilhamos o trabalho desenvolvido pelas línguas estrangeiras tanto dentro quanto fora da sala de aula, tanto dentro do coletivo de professores quanto a partir de nossas especificidades.

$N$ as nossas primeiras reuniões semanais para planejamento conjunto, dentre as reflexões e decisões partilhadas pelo grupo de professores pertencentes aos quatro componentes curriculares (Comunicação, Expressão e M ovimento, Ciências Exatas e da $\mathrm{N}$ atureza e Ciências H umanas), evidenciou-se a necessidade de direcionarmos os nossos trabalhos através de um tema gerador, de modo que a organização dos conteúdos pudesse gerar diálogos futuros e constantes entre os componentes e entre as próprias áreas específicas dentro de cada componente. Para este primeiro semestre, decidimos trabalhar com o tema "Direitos H umanos".

Como tema amplo e abrangente, permitiu-nos pensar em diversos assuntos para serem abordados em sala de aula. Enquanto componente curricular responsável pelo ensino e aprendizagem da língua materna e mais duas línguas estrangeiras, procuramos trabalhar conjuntamente. $\mathrm{N}$ a língua materna, trabalhouse a linguagem como forma de expressão e comunicação, como representação de marcas culturais a serem respeitadas (variantes linguísticas), adequação de uso da linguagem em diferentes contextos (linguagem coloquial e linguagem formal). No caso da língua

10 Destacamos que a elaboração de material próprio é possível no CAp/UFRGS devido à disponibilização de reprodução de materiais (fotocópias). 
espanhola, tratou-se da história dessa língua, das diferentes línguas cooficiais existentes na Espanha - inclusive como marca de resistência e de identidade -, da imposição linguística em grande parte da A mérica L atina com a chegada dos espanhóis à América. $\mathrm{N}$ a língua inglesa, refletiu-se sobre o uso da língua no âmbito internacional, ressaltando-se o uso do idioma para a comunicação com outros falantes não-nativos. Falamos também sobre a importância do conhecimento da língua inglesa para uma maior reflexão sobre a influência desse idioma na nossa língua materna - discussão que envolveu o professor de Português e reflexões sobre estrangeirismos presentes no português. Por meio desse trabalho conjunto, procuramos criar situações de reflexão sobre preconceitos linguísticos, a importância de conhecer outras línguas como forma de acesso a novos conhecimentos, reflexão sobre nossa própria cultura e melhor compreensão de outras culturas.

Além disso, considerando o tema gerador procuramos planejar as aulas do semestre definindo possíveis conteúdos temáticos que pudéssemos desenvolver em sala de aula. Como primeira proposta, pensamos em trabalhar temas que sempre tomassem como ponto de partida o próprio aluno como sujeito social, com uma história pessoal a ser compartilhada e valorizada, mesmo porque corroboramos as sugestões do Projeto de I mplementação da EJA-CA p/U FR GS e das Propostas Curriculares para a EJA de que com esse tipo de abordagem metodológica "[ o] aluno tem a chance de participar da elaboração conjunta do conhecimento, usando sua própria história como fonte e como objeto de aprendizado" (BRASIL, 2002a, p. 68).

$\mathrm{N}$ a programação das L E para esse primeiro semestre, definimos conjuntamente temas relacionados à apresentação pessoal, à apresentação da família, à relação do aluno com o trabaIho, ao direito do acesso à cultura.

No caso do Espanhol para esta primeira experiência, o planejamento das aulas e a organização do material foram feitos de forma a desenvolver as quatro habilidades (ler, falar, escutar 
e escrever). Distanciando-nos do foco estruturalista e mecanicista de ensino de línguas, procuramos desenvolver um material que: ${ }^{11}$

a) reunisse, sempre que possível, textos autênticos relacionados ao tema gerador e ao trabalho desenvolvido por outros componentes curriculares (propagandas contra o trabalho infantil, letra de música que fazia referência a trabalho escravo, fotos de famílias usadas pela propaganda...) para leitura e interpretação;

b) apresentasse propostas de pequenas produções orais e escritas explorando, ao máximo, os dados dos alunos (apresentações pessoais, apresentação da família, entrevistas com colegas de outras turmas,...);

c) permitisse a exploração de grupos lexicais e formas gramaticais a partir dos textos trabalhados e das necessidades para a produção oral e escrita (léxico sobre família, dados pessoais e profissão; formalização do uso de pronomes pessoais formalidade e informalidade, uso adequado de verbos como ser, estar e ter);

d) propusesse atividades com músicas de diferentes gêneros (desde as mais conhecidas até as menos conhecidas ou até desconhecidas pelos alunos) como forma de contribuir para 0 desenvolvimento da compreensão auditiva.

Além da proposta de material descrita acima, ressalta-se que, como forma de estimular a compreensão auditiva do aluno e aumentar o contato com o idioma falado, as aulas são dadas sempre em espanhol.

$\mathrm{N}$ as aulas de Língua Inglesa, o trabalho desenvolvido foi norteado pela proposta de desmistificar a língua inglesa e, assim, aproximar o aluno ao idioma. Considerou-se o conhecimento prévio dos alunos como ponto de partida e, para isso, realizaram-se tarefas que os ajudassem a conscientizar-se da existência desse conhecimento prévio. A apropriação da língua foi trabalhada por meio de observação do uso do idioma inglês no

11 Fazemos aqui apenas uma descrição superficial da proposta do material e do encaminhamento realizado em sala de aula, visto que o objetivo principal do artigo é compartilhar uma visão geral do espaço das línguas estrangeiras na EJA-CAp/U FRGS. 
cotidiano brasileiro e por meio de trabal ho com cognatos do português e do inglês. Para este último, priorizou-se o uso da língua portuguesa como auxílio na leitura de textos em inglês.

O s assuntos discutidos na aula de Língua Inglesa também foram gerados pelo tema "Direitos H umanos". As atividades de aula, sempre que possível e principalmente respeitando as limitações lingüísticas dos alunos, abrangeram as habilidades:

- de compreensão oral, incluindo, gravações de materiais didáticos em CD e músicas;

- de leitura, trabalhada a partir de textos autênticos (textos de informação tirados da I nternet) e de textos criados e adaptados para os assuntos discutidos em sala de aula;

- de escrita, com a produção de pequenos textos sobre o cotidiano e família;

- de oralidade, trabalhada por meio de entrevistas com colegas e visando sempre oportunizar o trabalho em grupos.

A lém disso, houve leitura de textos pela professora e trabaIho de pronúncia de elementos básicos da língua a fim de promover uma familiarização dos alunos com os aspectos fonológicos da língua inglesa.

Em vários momentos também se trabalhou com a análise dos tópicos abordados em aula por meio de geração de debates e de reflexões escritas, sendo esses realizados na língua materna. Tal estratégia foi usada para que não se deixasse de aprofundar tópicos de interesse dos alunos por falta de conhecimento linguístico para fazê-los na língua alvo.

Contudo, vale ressaltar que algumas estruturas da língua inglesa foram trabalhadas dentro de temas do cotidiano do aluno como a rotina semanal e a sala de aula. $\mathrm{H}$ ouve necessidade de se trabalhar dentro desses pequenos temas a fim de apresentar estruturas básicas do inglês como, pronomes pessoais, adjetivos possessivos e verbo to be e também estruturas comunicativas como saudações e apresentações.

A necessidade de utilizar-se também materiais "facilitados", ou seja, criados ou adaptados pelo professor para mais fácil 
compreensão por parte dos alunos, surgiu como uma forma de criar um sentimento de autonomia na sala de aula.

D evemos destacar que dentro do trabalho com a língua espanhola e inglesa, houve constantemente a necessidade de readequação entre a proposta inicial de progressão de conteúdos e a realidade da sala de aula. A volta à escola para os alunos nesse primeiro semestre, representou uma re-escolarização em diversos sentidos. $O \mathrm{~s}$ alunos precisaram se adaptar à proposta pedagógica do CA p/U FR GS, em que os papéis de professores detentores de conhecimento e de alunos receptores desse conhecimento - característicos do ensino bancário - não tem mais espaço.

\section{O ensino simultâneo da língua espanhola e da língua inglesa: congruências, dissonâncias e desafios}

0 trabalho desenvolvido até o momento com duas línguas estrangeiras na EJA-CA p/U FR GS tem revelado aspectos muito interessantes. Por um lado, temos congruências que ocorrem naturalmente já que existem objetivos comuns definidos por uma Proposta de I mplementação associada a um diálogo semanal entre as professoras quanto ao planejamento das aulas. Por outro, notamos que 0 ensino e a aprendizagem de espanhol e inglês apresentam certas especificidades lingüísticas e de aquisição.

É muito comum, na fala dos alunos, a comparação entre os dois idiomas. ${ }^{12}$ Entendemos este fato como algo real, visto que a língua espanhola apresenta uma proximidade muito maior com a língua portuguesa já que ambas são de origem latina. Além disso, Eres Fernández (apud DU RÃO, 2002) baseada em pesquisas sobre a proximidade entre 0 espanhol e o português, aponta que os alunos conseguem compreender $58 \%$ do idioma escrito, os outros $42 \%$ devem ser considerados e trabalhados com os alunos.

12 Em questionário aplicado para os alunos do EF 3 e para o EM 1 sobre as percepções, críticas e sugestões quanto às aulas de LE, foi comum os alunos mencionarem que têm mais facilidade em aprender a língua espanhola do que a língua inglesa. 
D esde a primeira aula eles percebem que o espanhol é mais acessível quanto à sua compreensão, por exemplo. Torna-se um constante desafio mediar essa relação entre aprender um idioma próximo à língua materna - no caso o espanhol - e aprender outro mais distante, como é o caso do inglês.

U ma marca que diferencia uma maior facilidade ou não de compreensão da língua estrangeira é o uso da língua materna em sala de aula. Como assinalado anteriormente, nas aulas de Espanhol é possível trabalhar quase o tempo todo usando a língua espanhola, enquanto nas aulas de Língua Inglesa, a língua materna é usada predominantemente pela professora.

Percebemos que é possível o planejamento e o desenvolvimento conjunto de alguns temas e até mesmo propor atividades que envolvam os dois idiomas (como será descrito mais abaixo). Entretanto o ritmo e a profundidade como os aspectos linguísticos das duas línguas serão trabalhados, por exemplo, distanciam-se de acordo com as necessidades, facilidades e/ou dificuldades dos alunos.

Como defendemos ao longo deste artigo, acreditamos que o acesso a uma ou mais línguas estrangeiras é importante na formação do aluno, permitindo acesso a novas informações, à construção de novos conhecimentose à construção da cidadania. Percebemos que é fundamental incluirmos isso em nossa prática docente e construir essa consciência junto aos alunos. Por outro lado, beneficiamo-nos ao considerar as impressões dos alunos diante da aprendizagem das duas línguas, aprendendo a respeitar certas facilidades e/ou dificuldades para não criarmos um ambiente de priorização de um idioma em detrimento de outro.

Trabalhar simultaneamente com os dois idiomas pode pa recer desafiador - e talvez seja - tanto para o professor quanto para o aluno. O utro motivo de utilizar os dois idiomas é que no mundo atual, cada vez mais materiais bilíngües fazem parte do nosso cotidiano - cartazes bilíngües em qualquer aeroporto internacional, preenchimento de formulários bilíngües etc.

L evando isso em consideração, desenvolvemos um cartaz bilíngüe em que os alunos trabal haram em duplas entrevistando 
os colegas e escrevendo os dados no cartaz. 0 cartaz era inicialmente uma proposta de prática oral para o espanhol, porém surgiu a idéia de se colocarem os dados de identificação nas duas línguas e utilizar o cartaz para posterior apresentação destas mesmas perguntas em inglês. Foi uma experiência interessante, pois a atividade forneceu uma ferramenta extra para que os alunos inferissem os significados das palavras em inglês no segundo momento. Eles não somente inferiram significados através das informações pessoais já contidas no cartaz, mas também e principalmente o fizeram por meio do vocabulário de espanhol que tinham aprendido na aula anterior.

Este é só um exemplo de atividade, mas essa experiência nos mostrou que desenvolver atividades em conjunto, se levadas em consideração as especificidades de cada idioma, pode enriquecer a aula de LE. Assim, podemos encontrar formas de aproveitar os conhecimentos prévios e recém adquiridos em uma língua estrangeira para auxiliar o aprendizado de novos elementos na outra língua estrangeira.

\section{Considerações finais}

Como dissemos na introdução deste artigo, entendemos que para situar o ensino de línguas estrangeiras na educação de jovens e adultos do CA p/U FR GS precisávamos compreender o seu papel num contexto mais amplo, ou seja, o espaço destinado ao ensino de LE na educação de forma mais geral.

Certamente, a EJA-CA p/UFR GS entende 0 ensino de LE como algo tão integrado ao currículo quanto todas as demais áreas específicas que formam os componentes curriculares do Colégio. Além disso, a flexibilidade e a abertura oferecida pela Proposta de I mplementação da EJA, as reuniões semanais com os demais colegas dos outros componentes curriculares e as reuniões entre os profissionais de nosso próprio componente de Comunicação criaram um ambiente de constantes trocas e reflexões sobre a nossa prática. 
O utro objetivo nosso era compartilhar experiências vivenciadas neste primeiro semestre com as línguas estrangeiras na EJA-CAp/U FRGS. A partir de nosso planejamento e principalmente da observação e reflexão das necessidades específicas dos alunos, dispusemo-nos a repensar semanalmente a seqüência das aulas e dos conteúdos a serem trabalhados.

Entre um de nossos desafios, está manter o foco conjunto entre o ensino de língua espanhola e da língua inglesa, associado às outras áreas específicas dos demais componentes curriculares. Lembramos que parte desse desafio consiste em desenvolver semanalmente um material próprio que reflita as questões a serem discutidas em sala de aula, em consonância com os demais componentes e ao mesmo tempo atendendo as especificidades das LE e a realidade da sala de aula.

O espaço destinado ao fazer pedagógico da EJA no CAp/ U FR GS propiciou muita liberdade, inspiração e motivação aos professores. A constante troca de experiências gerou uma grande integração entre os componentes curriculares em muitos momentos. Acreditamos que isso se deveu ao fato de termos trabalhado com temas geradores, que não apenas serviram como "bússola", mas também como base para a elaboração dos conteúdos. Le vando em consideração que temos uma estrutura que propicia um desenvolvimento e uma organização que incentiva a prática interdisciplinar, sabemos que o trabalho pode ser continuamente aprimorado, pois reconhecemos que nossa experiência é muito recente.

\section{Referências}

BRASIL . M inistério da E ducação. L ei de D iretrizes eBases da E ducação N acional. Brasília, 1996. D isponível em < http://www. planalto.gov.br/ ccivil_03/Leis/ L9394.htm>. A cesso em: 06 setembro 2008.

. M inistério da E ducação. Secretaria da E ducação M édia e Tecnológica. Parâmetros curriculares nacionais, códigos esuas tecnologias. Língua Estrangeira M oderna. B rasília, p. 146-153, 1999. 
. M inistério da Educação. Secretaria de E ducação Fundamental. Proposta C urricular para a Educação deJ ovenseA dultos o segundo segmento do ensino fundamental. Brasília, 2002a. D isponível em < http://portal. mec.gov.br/secad/arquivos/pdf/eja_livro_01.pdf> . A cesso em: 08 novembro 2008.

. M inistério da Educação. Secretaria de E ducação Fundamental. Proposta C urricular para a Educação deJ ovenseA dultos. o segundo segmento do ensino fundamental. L íngua Estrangeirana Educação deJ ovenseA dultos. Brasília, 2002b. vol. 2. D isponível em < http://portal.mec.gov.br/secad/ arquivos/pdf/eja/propostacurricular/segundosegmento/vol2_lingua estrangeira.pdf>. A cesso em: 08 novembro 2008.

. Parecer C NE/C EB no 11 de 10 demaio de2000. D ispõe sobre as Diretrizes Curriculares N acionais para Educação de J ovens e A dultos. R elator Conselheiro: Carlos R oberto J amil Cury. D isponível em < http:/ /portal.mec.gov.br/secad/arquivos/pdf/eja/ legislacao/parecer_11_2000. pdf > . A cesso em: 06 de setembro 2008.

. Resolu ção C N E/C EB no1 de5 dejunho de2000. Estabelece as Dire trizes Curriculares $\mathrm{N}$ acionais para a E ducação de J ovens e A dultos. D isponível em < http://portal.mec.gov.br/cne/arquivos/pdf/CEB 012000. pdf> . A cesso em: 06 setembro 2008.

. Secretaria da E ducação Fundamental. Parâmetros C urriculares $\mathrm{N}$ acionais. terceiro e quarto ciclos do ensino fundamental: língua estrangeira. Brasília, 1998.

- Secretaria de Educação Básica. O rientações curriculares para 0 ensino médio: linguagens, códigos e suas tecnologias. B rasília, 2006.

CE LAN I, M aria Antonieta Alba. As línguas estrangeiras e a ideologia subjacente à organização dos currículos da escola pública. C laritas, São Paulo, n. 1, 1994.

CH AGAS, R aimundo Valnir Cavalcanti. Evolução do Ensino das L ínguas no Brasil. In: D idática Especial delínguas M odernas. 2aㅡ ed. São Paulo: N acional, $19 \overline{7} \overline{9}$.

COLÉGIO DE APLICAÇÃO-U FR GS. Proposta para implementaçãoda modalidadedeeducação para jovenseadultosnoC olégio de A plicaçãoda U FR GS - EJA/C A p/U FR GS. Porto A legre, 2008. (inédito) 
D U R Ã O, Adja Bal bino A morim Barbieri. ¡Por detrás de la transparencia existe una opacidad! L a lectura por estudiantes brasileños de textos redactados en español. A nuario brasileñodeestudioshispánicos. Brasília, n. 12, p. 13-28, 2002.

LEFFA, Vilson. $\mathrm{O}$ ensino das línguas estrangeiras no Contexto $\mathrm{N}$ acional. Contexturas, São Paulo, n. 4, p. 13-24, 1999.

PICAN ÇO, D eise Cristina de L ima. H istória eensino de espanhol (19421990): as interfaces do ensino da língua espanhola como disciplina escolar a partir da memória de professores, métodos de ensino elivros didáticos no contexto das reformas educacionais. Curitiba: E ditora daU FPR , 2003. 